\title{
Introduction to the Goldberg Festschrift
}

\author{
E. N. Glass • D. C. Robinson
}

Published online: 30 August 2011

(C) Springer Science+Business Media, LLC 2011

2012 marks the 15th anniversary of the publication of the famous "Goldberg-Sachs theorem" [1], and the 16th anniversary of Josh Goldberg's $\mathrm{PhD}$ award. It is therefore particularly fitting that Josh's many contributions to the study of general relativity are honoured now with this collection of papers by friends and colleagues.

Josh has described his graduate student years and the work done by himself and the Syracuse University (SU) relativity group in a recent article [2]. Josh's thesis advisor was the doyen of SU relativity, Peter Bergmann, and his PhD research was on conservation laws and equations of motion. This reseach led to his first relativity publication [3]. Conservation laws and equations of motion have remained dear to his heart and they have been the subjects of numerous papers by him. In 1980 he provided an excellent summary of his views on these topics in an important article in the Einstein centenary volume [4]. His second relativity paper [5] was quickly influential and made a major improvement to the understanding of gravitational radiation at that time. Gravitational radiation theory, canonical formalisms for classical and quantum gravity, and the history of general relativity are among the areas to which he has made illuminating contributions over many years. All of these topics are at least touched upon in this collection of papers.

After completing his PhD, Josh spent four years at the Armour Research Foundation in Chicago. He then moved to the Aerospace Research Laboratory at Wright-Patterson Air Force base near Dayton, Ohio, where he set up a relativity group. In a historically valuable paper, Josh has recalled his time there [6]. A number of the authors in this

\footnotetext{
E. N. Glass $(\varangle)$

Department of Physics, University of Michigan, Ann Arbor, MI, USA

e-mail: englass@umich.edu

D. C. Robinson

Mathematics Department, King's College London, Strand, London WC2R 2LS, UK

e-mail: david.c.robinson@kcl.ac.uk
} 
collection testify to the importance of the role Josh played when the U.S. Air Force supported research in general relativity. The support provided was international in scope, particularly significant in Europe, and funded highly creative developments in the subject. Many of the articles in this festschrift are written by colleagues whose ties with Josh were formed as a direct or indirect consequence of his international activities at that time.

In 1963 Josh returned to the physics department at SU and has been there ever since. Over many years he provided leadership in sustaining and developing both the relativity group and the department. For a long period he was Chairman and actively concerned with the governance of the University and other professional bodies. Current and former SU faculty and postdocs, and former SU students have provided many of these articles. The two of us were graduate students at SU in the 1960's and Josh was our thesis advisor. We worked with him on the Newman-Penrose constants, and during those years he wrote a number of papers on conservation laws and invariant transformations related to the constants. One offshoot of this particular interest was the highly cited collaboration on spin-s spherical harmonics [7]. The physical interpretation of these constants is still not clear cut and continues to be explored, particularly in relation to gravitational collapse and black hole equilibrium end states.

In 1965 the department relocated from the old Steele Hall building to a newly built one, the current Physics building. Peter Bergmann, Josh, and a few minions such as we, were ensconced in a small suite of rooms on the second floor. Included in the suite was a discussion area with blackboards, a couch, and a row of filing cabinets containing an amazing and valuable collection of preprints and reprints-rifled through by students over many years. Under the leadership of Peter and Josh, this suite became a particularly informal, friendly, and stimulating centre for general relativity at Syracuse. It is here that Josh spent many years contributing to the field to which he has devoted much of his life.

In 2009 his paper with Ray Sachs, mentioned above, was republished as a "Golden Oldie" in this journal [1]. This landmark paper is the result of one of Josh's many fruitful collaborations. We have mentioned here only the main themes of Josh's research and a small number of his papers. The full list can be found on his SU home page.

During his retirement Josh has followed the major developments in the field, particularly those related to cosmology and astrophysics. He has made many important contributions to general relativity but we should also note that he has always been actively concerned with the rights and needs of others, and the cultural life of Syracuse. In all this he has been fortunate to enjoy the wholehearted support of his wife Gloria. Josh and Gloria are noted for their warmth, the generosity of their hospitality and the breadth of their cultural interests. We wish them all the best for the future.

\section{References}

1. Goldberg, J.N., Sachs, R.K.: Acta Phys. Polon. Supp. 22, 13 (1962). A theorem on petrov types, reprinted in Gen. Relativ. Gravit. 41, 421 (2009)

2. Goldberg, J.N.: Syracuse 1949-52. In: Eisenstaedt, J., Kox, A.J. (eds.) The Universe of General Relativity, pp. 357-371. Birkhäuser, Boston (2005) 
3. Goldberg, J.N.: Strong conservation laws and equations of motion in covariant field theories. Phys. Rev. 89, 263 (1953)

4. Goldberg, J.N.: Invariant transformations, conservation laws, and energy-momentum. In: Held, A. (ed.) General Relativity and Gravitation, One Hundred Years after the Birth of Albert Einstein, Plenum Press, New York (1980)

5. Goldberg, J.N.: Gravitational radiation. Phys. Rev. 99, 1873 (1955)

6. Goldberg, J.N.: U.S. Air Force support of general relativity 1956-72. In: Eisenstadt, J., Kox, A.J. (eds.) Studies in the History of General Relativity, Einstein Studies, vol. 3, Birkhauser, Boston (1992)

7. Goldberg, J.N., Macfarlane, A.J., Newman, E.T., Rohrlich, F., Sudarshan, E.C.G.: Spin-s spherical harmonics. J. Math. Phys. 8, 2155 (1967) 